\title{
DEM in 3D Simulation of Influencing Factors of Deformation Properties and p-y Curves of a Laterally Loaded Pile
}

\author{
Xiao Zhao-ran ${ }^{1}$ and Wang Junlin ${ }^{2}$ \\ ${ }^{1}$ School of Civil Engineering and Architecture, Henan University of Tecnology, Zhengzhou \\ ${ }^{2}$ School of Environmental and Water conservancy, Zhengzhou University, Zhengzhou
}

\begin{abstract}
Based on structural similarity principles, a scale model of a laterally loaded pile was established to numerically simulate and study the problem of lateral soil-pile interaction by distinct element method in 3 dimensions. Level displacements of the pile and soil resistance around the pile related to the factors of the pile's diameter, the pile's rigidities and soil properties. According to the above distinction classification method, the factors of the pile's diameter, the pile's material rigidities and internal frictional coefficient of soil around the pile were analyzed in detail to find different quantity influences on the mechanics characters of horizontal displacements of the pile and the p-y curve.
\end{abstract}

Keywords: laterally loaded pile; p-y curves; distinct element method; reducedscale model.

\section{Introduction}

Piles of buildings mainly withstand vertical axial loads in general foundation engineering, but piles in river ports, bridges, high buildings, offshore oil extraction platforms, shoring buildings and aseismatic buildings also simultaneously withstand horizontal loads of wind force, wave force, ship impacting force, earth pressure, seismic force and so on. In the oceanic engineering, the problems of piles and their stabilities are concerned mostly by design apartments currently, since $40 \% \sim 50 \%$ of a oceanic engineering' $\mathrm{s}$ cost is focused on groundwork ${ }^{[1]}$. At present, the horizontal ultimate bearing and the bearing behavior of a laterally loaded pile are taken seriously but not settled well in geological engineering, because of laterally loaded piles' wide application. Level distortion of the pile and the p-y curve relate to the factors of the pile's diameter, the pile's rigidities (material) and soil conditions. In order to determine bearing capacity of the pile, it is necessary to numerically analyze scientifically and reasonably different quantity influences by the factors of the pile's diameter, the pile's rigidities (material) and soil conditions on the mechanics characters of horizontal displacements of the pile and the p-y curve.

The horizontal bearing properties of a pile largely depend on deformation characteristics of soil around the pile, and its capabilities of bearing horizontal loads 
greatly relate to microscopic mechanical properties and the relation between microscopic structure and macroscopic mechanical phenomenon of soil ${ }^{[2]}$. With the aid of distinct element theory's special advantage in simulating mechanical problems of dispersed medium, the microscopic structure of soil around a pile has been simulated and analyzed with distinct element method while the pile is bearing lateral loads in the article. The above influent factors could be reasonably considered according to the rules of the lateral deformation of the pile and the p-y curve, in order that the design scheme was chose reasonably and the property of bearing lateral loads of the pile-soil system were enhanced.

\section{Model Establishments}

\subsection{Establishing the Reduced-Scale Model}

The loads and stresses of the pile-soil system were mainly produced by its own weight, and they also controlled the distortion and the destruction of the structure. But a less sizes model could not reappear the characteristic of the prototype, since its gravity was much lower than the prototype. The only way of solving this problem was enhancing the gravity of the reduced-scale model so as to equal the prototype' s gravity. So the stress-strain relationship of the model was the same as that of prototype.

A $1 / \mathrm{n}$ ( $\mathrm{n}$ was the reduced ratio) pile-soil reduced-scale model has been simulated in distinct element method under a condition of the acceleration of $\mathrm{ng}$ ( $\mathrm{g}$ is gravity acceleration) or the density gravity of $n \gamma$ ( $\gamma$ is density gravity of the raw material). Since it was absolutely equivalent between the gravitational fields of the model and the prototype, the model had equal stress and strain, similar distortion and same destructive mechanism with the prototype. Therefore, the reduced-scale model could reappear the characteristics of the prototype. At the same time, soil was divided into inner layer soil near the pile and outer layer soil far away the pile in order not to destroy the pile-soil constitutive relationship. The grain diameter of the former soil was close to grain diameter of middle sand, and the grain diameter of the latter soil was slightly bigger than the former. Partial reduced-scale factors of the reduced-scale model relative to its prototype were listed in Table $1^{[4]}$.

Table 1. Reduced-scale factors of a reduced-scale model relative to its prototype

\begin{tabular}{ccc}
\hline Measure & Prototype & $\begin{array}{c}\text { Reduced-scale model } \\
\text { (gravitational acceleration of ng) }\end{array}$ \\
\hline Length & 1 & $1 / \mathrm{n}$ \\
Area & 1 & $1 / \mathrm{n}^{2}$ \\
Volume & 1 & $1 / \mathrm{n}^{3}$ \\
Quality & 1 & $1 / \mathrm{n}^{3}$ \\
Density & 1 & 1 \\
Acceleration & 1 & $\mathrm{n}$ \\
Force & 1 & $1 / \mathrm{n}^{2}$ \\
Stress & 1 & 1 \\
Strain & 1 & 1 \\
\hline
\end{tabular}




\subsection{Choice of Calculation Parameters}

According to experiment conditions in reference [4], the size of the model box was $45.7 \mathrm{~cm}$ (length) $\times 25.7 \mathrm{~cm}$ (width) $\times 25.7 \mathrm{~cm}$ (high). The pile diameters of the model piles were $0.6 \mathrm{~cm}, 1.2 \mathrm{~cm}$ and $2.4 \mathrm{~cm}$, and the length was $16.8 \mathrm{~cm}$. Under the acceleration of $50 \mathrm{~g}(\mathrm{n}=50)$, the diameters of prototype piles corresponding to that of the model piles were $0.3 \mathrm{~m}, 0.6 \mathrm{~m}$ and $1.2 \mathrm{~m}$, and the length was $8.4 \mathrm{~m}$.

Sand in the model box was formed by rigid granules, and the box was made from walls. There were normal and tangential distortion rigidities and frictional coefficients among granules and walls. The tangential and normal rigidities of walls were equal. The rigidities of four peripheral walls were10 times of the rigidities of sand, and the rigidities of the bottom wall were 10 times of peripheral walls. Parameters of the model were listed in Table 2. It is necessary to point out that the parameters of soil and pile foundation were user-defined in the DEM numerical simulation, and they were not their own real physical indexes. The model constitution was shown in Fig. 1. The formed granules were balanced under their own gravity (The acceleration of gravity was $50 \mathrm{~g}$ ). The granule aggregate was about $16.8 \mathrm{~cm}$ high, the porosity percent of soil was $38.9 \%$, and the porosity ratio of soil was 0.637 after being balanced.

\subsection{Loading Manner of the Model}

The loading mode of continuous classification that was the same as the single pile experiment of vertical static loads was adopted in the model formed under itself gravity, i.e. the result documents were saved after the pile-soil system was balanced fully under every level load, and then next load was forced. The simulation loads of the model were divided into ten levels, and the ordinal steps were $20 \mathrm{~N}, 28 \mathrm{~N}, 36 \mathrm{~N}, 44 \mathrm{~N}$, $52 \mathrm{~N}, 60 \mathrm{~N}, 68 \mathrm{~N}, 72 \mathrm{~N}$, $76 \mathrm{~N}$ and $80 \mathrm{~N}$. On the base of the reducedscale parameters in Table 1, external loads

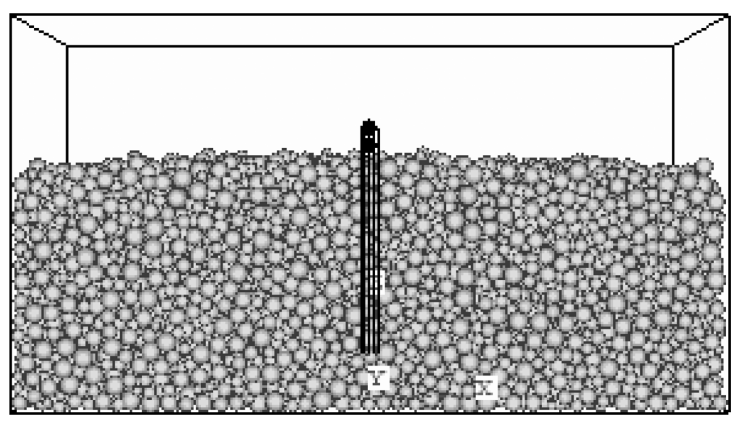

Fig. 1. The distinct element model in 3D of a laterally loaded pile forced on the model were $50 \mathrm{kN}, 70 \mathrm{kN}, 90 \mathrm{kN}, 110 \mathrm{kN}, 130 \mathrm{kN}, 150 \mathrm{kN}, 170 \mathrm{kN}$, $180 \mathrm{kN}, 190 \mathrm{kN}$ and $200 \mathrm{kN}$ in turn from the point of view of the prototype.

\section{Results Analysis of Numerical Simulation}

In order to reduce the dimension effect of the reduced-scale model, partial coordinates used dimensionless form. In figures y was the lateral displacement on top of the pile, 
Table 2. The collection table of basic factors of the distinct element model in 3D

\begin{tabular}{lcccccc}
\hline Types & $\rho$ & $\mathrm{R}$ & $\mathrm{M}$ & $K_{s}$ & $K_{n}$ & $\mu$ \\
\hline Sand & 2650 & $1.3 \sim 3.0$ & 1.85 & $1.0 \mathrm{e} 4$ & $1.0 \mathrm{e} 4$ & $0.6 / 0.8 / 1.0$ \\
Pile & 3000 & $6.0 / 12.0 / 24.0$ & & $\begin{array}{c}5.0 \mathrm{e} 4 / 5.0 \mathrm{e} \\
5 / 5.0 \mathrm{e} 6\end{array}$ & $\begin{array}{c}5.0 \mathrm{e} 4 / 5.0 \mathrm{e} 5 / 5.0 \\
\mathrm{e} 6\end{array}$ & 0.7 \\
\hline
\end{tabular}

Note: $\rho$-density of granules $\left(\mathrm{kg} \cdot \mathrm{m}^{-3}\right)$; $\mathrm{R}$--radius of granules $(\mathrm{mm})$; M--magnification factor of granule radius; $K_{s}--$ Tangential rigidity $\left(N \cdot m^{-1}\right) ; K_{n}--$ normal rigidity $\left(N \cdot m^{-1}\right) ; \mu$-frictional coefficient.

$\mathrm{z}$ represented the distance from some position to the head of the pile, D was the diameter of the model pile, and $\mathrm{H}$ was the length of the model pile.

\subsection{Effect Analysis of Diameter of the Pile}

The normal and tangential stiffness of the pile was supposed to be $500 \mathrm{kN} \cdot \mathrm{m}^{-1}$, diameters of $0.3 \mathrm{~m}, 0.6 \mathrm{~m}$ and $1.2 \mathrm{~m}$ of the pile were chose to calculate and analyze.

\subsubsection{Effect of Diameter of the Pile on the Flex Displacement of the Pile}

Fig. 2 told us that the pile size had notable effect on the flex curve of lateral displacement of the pile. The pile diameter was the bigger, the lateral displacement of the single pile was the smaller under the same lateral load. The lateral displacement on top of the pile increased by $55 \%$ when the pile diameter reduced from $0.6 \mathrm{~m}$ to its half; the lateral displacement on top of the pile reduced by $87 \%$ when the pile diameter increased from $0.6 \mathrm{~m}$ to its two times. Besides, the model pile gradually became from an elastic pile to a rigid pile with increasing the pile diameter. Therefore, enlarging the pile diameter could obviously control the lateral displacement of the

Lateral displacements of the pile body, $y / D$

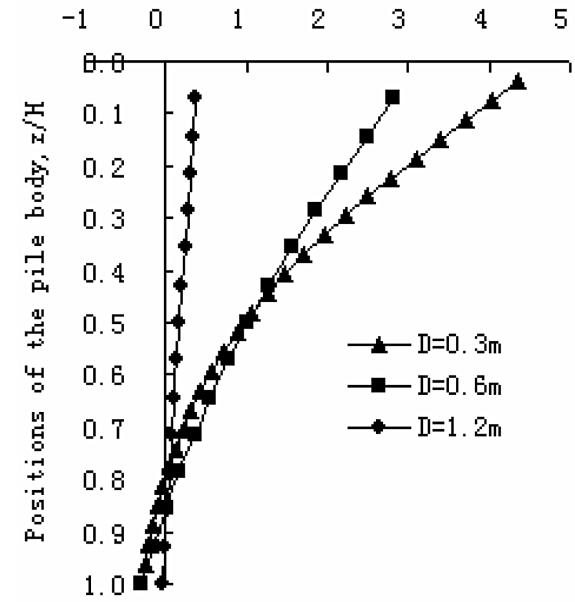

Fig. 2. Effect of diameter of the pile on flex displacement distribution of the pile pile. 


\subsubsection{Effects of Diameter of the Pile on the p-y Curve the Pile}

The following p-y curves were chose at the positions of distances $0.31 \mathrm{~L}, 0.46 \mathrm{~L}$ and $0.62 \mathrm{~L}$ from the top of the pile. The diameter (or width) of the pile was one of the effect parameters to analyze the p-y curve.

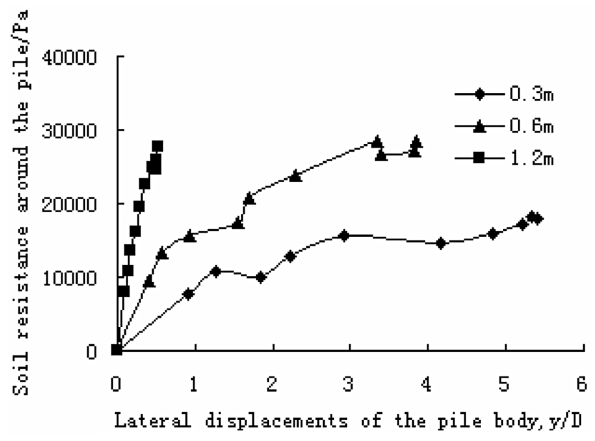

(a) Distance from the top of the pile was

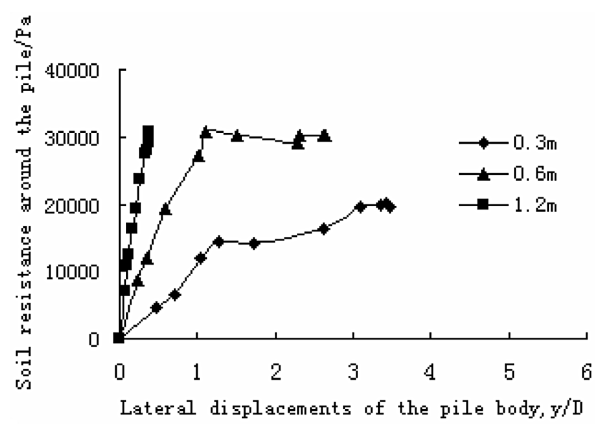

(b) Distance from the top of the pile was $0.46 \mathrm{~L}$

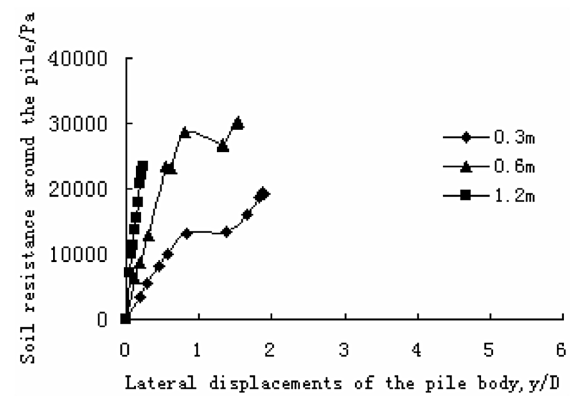

(c) Distance from the top of the pile was $0.62 \mathrm{~L}$

Fig. 3. Effect of diameter of the single pile on the p-y curves of the pile

The pile diameter was the bigger; soil resistance $\mathrm{p}$ was the bigger under definite situations in Fig. 3. The relationship between the ultimate soil resistance around the pile and the pile diameter was roughly linear. The emulational results of the model pile comparatively approached the Broms's viewpoints ${ }^{[5]}$.

\subsection{Effect Analysis of Connected Stiffness of the Pile}

The bearing force of the pile was relevant to its elastic modulus, and the elastic modulus was corresponding to the connected stiffness of the model pile. The pile diameter was unchangeable and while analyzing the effect of the pile connected stiffness on laterally loaded properties of the pile, i.e. $\mathrm{D}=0.6 \mathrm{~m}$, but the normal stiffness and tangential stiffness in the connected pile model were variational. The connected stiffness of the pile was listed in Table 3 . 


\subsubsection{Effect of Connected Stiffness of the Pile on the Flex Displacement of the Pile}

The simulation result of Fig. 4 indicated that the flexibility of the pile and the displacement along the pile in the lateral load direction were the bigger while the connected stiffness of the pile were the smaller. But the pile displacement was not sensitive to its connected stiffness, which it may be relevant to being more rigid of the pile.

\subsubsection{Effect of Connected Stiffness of the Pile on the p-y Curve of the Pile}

It was supposed that the $p-y$ curve of the laterally loaded pile was not relevant to the pile stiffness in references of $[6,7]$. But the analysis results of Briaud $^{[8]}$ and others indicated stiffness of the pile had some effect on the p-y curve of the single pile in the shallow soil.

Simulation results were shown in

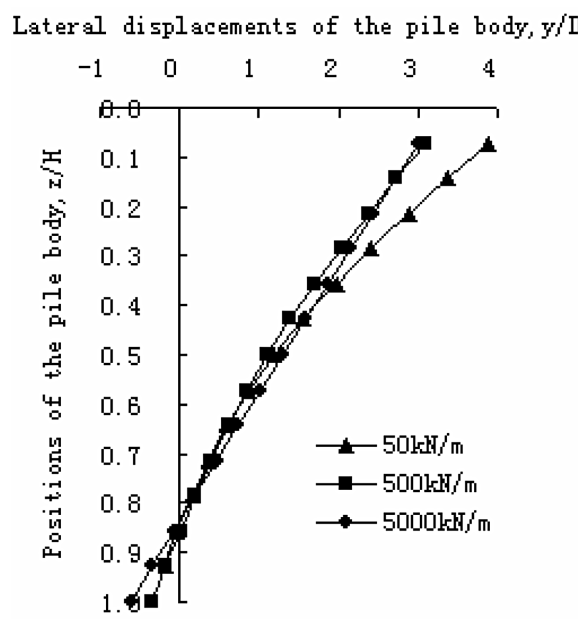

Fig. 4. Effect of connected stiffness of the pile on flex displacement distribution of the pile Fig. 5.

The analytical results indicated the p-y curve of the laterally loaded single pile was not sensitive to the material modulus, i.e. connected stiffness. This conclusion was consistent with that in reference [9]. But the connected stiffness was the bigger, the lateral resistance of soil would be developed deeper, so the transform point of the resistance moved down, and the lateral resistance of below soil increased, which was beneficial to enhancing the lateral bearing capacity of the pile.

\subsection{Effect Analysis of Internal Frictional Coefficient of Soil}

The mainly parameters of soil were water content, density, void ratio, plastic index, liquid index, compression coefficient, compression modulus, internal frictional angle and so on. Only the internal frictional coefficient of soil was considered while simulating in the article. In order to analyze the effect of internal frictional angle of

Table 3. The normal stiffness and tangential stiffness of the pile

\begin{tabular}{cccc}
\hline Number & 1 & 2 & 3 \\
\hline$K_{s} / k N \cdot m^{-1}$ & 50 & 500 & 5000 \\
$K_{n} / k N \cdot m^{-1}$ & 50 & 500 & 5000 \\
\hline
\end{tabular}




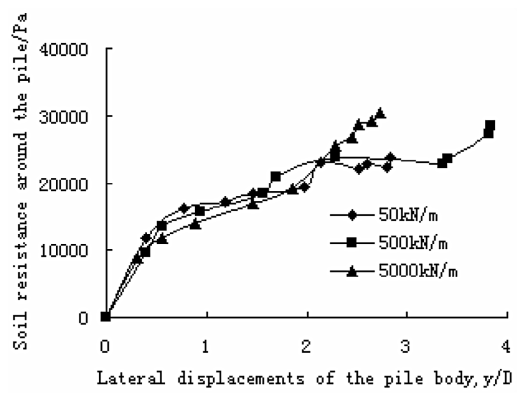

(a) Distance from the top of the pile was $0.31 \mathrm{~L}$

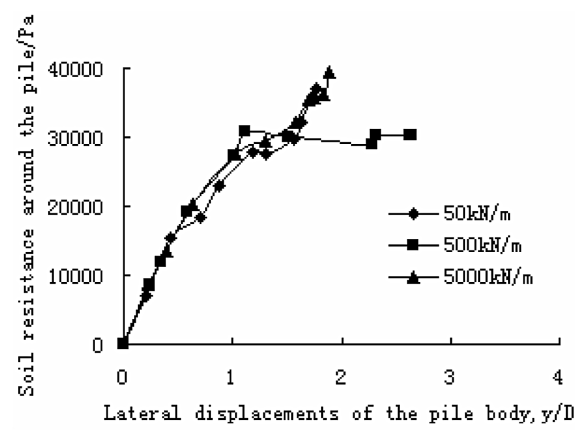

(b) Distance from the top of the pile was $0.46 \mathrm{~L}$

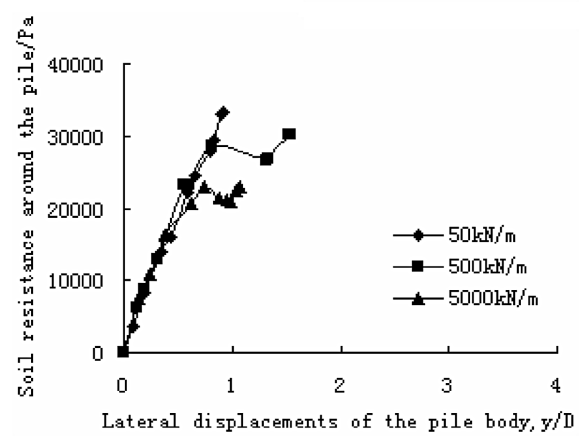

(c) Distance from the top of the pile was $0.62 \mathrm{~L}$

Fig. 5. Effect of connected stiffness of the single pile on the p-y curves of the pile

Table 4. Parameters of internal frictional coefficients of soil

\begin{tabular}{cccc}
\hline Number & 1 & 2 & 3 \\
\hline Internal frictional coefficients $\mu$ & 0.6 & 0.8 & 1.0 \\
\hline
\end{tabular}

soil on the lateral bearing character of the pile, normal stiffness and tangential stiffness were supposed to be $500 \mathrm{kN} \cdot \mathrm{m}^{-1}$, and the diameter of the pile was $0.6 \mathrm{~m}$. Three selective internal frictional coefficients were listed in Table 4.

\subsubsection{Effect of Internal Frictional Coefficient of Soil on the Flex Displacement of the Pile}

The effect of the character of the soil around the pile on the flex displacement distribution of the pile was little. The lateral displacement of the pile did not reduce notably when the internal frictional coefficient of soil gradually increased, which was shown as in Fig. 6. 


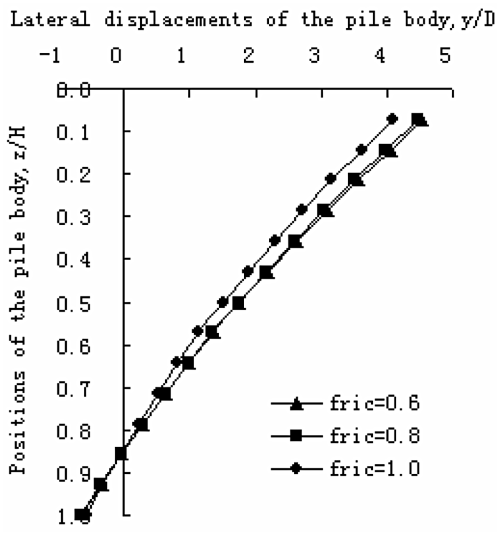

Fig. 6. Effect of internal frictional coefficient of soil on flex displacement distribution of the pile

\subsubsection{Effect of Internal Frictional Coefficient of Soil on the p-y Curve of the Pile}

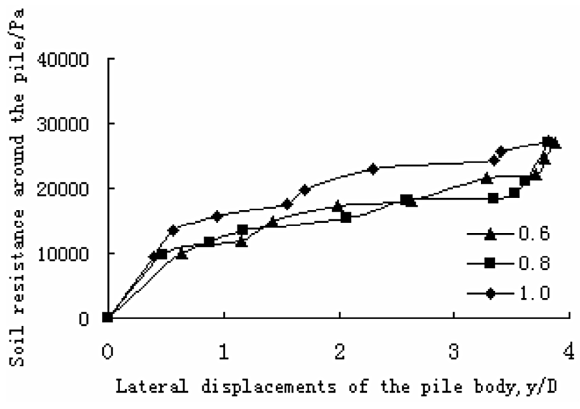

(a) Distance from the top of the pile was $0.31 \mathrm{~L}$

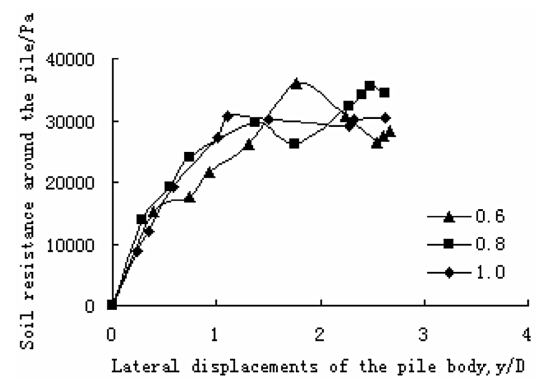

(b) Distance from the top of the pile was $0.46 \mathrm{~L}$

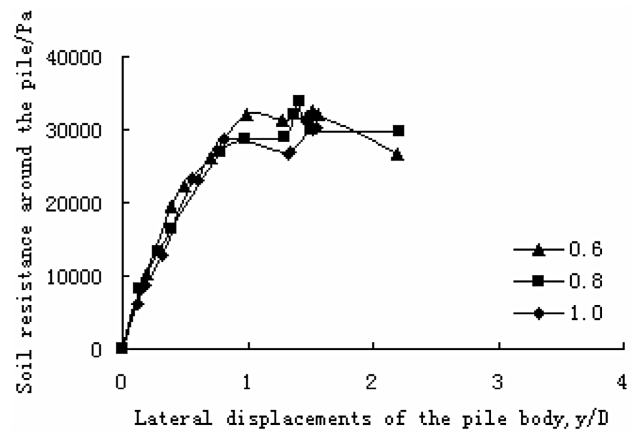

(c) Distance from the top of the pile was $0.62 \mathrm{~L}$

Fig. 7. Effect of internal frictional coefficient of soil on the p-y curves of the pile 


\section{Conclusions}

Compared with other numerical simulation methods, the superiority of distinct element method in 3D was that it was only necessary to assign some microscopic basic parameters (such as contact rigidities and frictional coefficient and so on) between granules when it was used to cope with the problem of pile-soil interaction under lateral loads. The constitutive relationship of the pile-soil system could formed automatically, thus choosing the constitutive relationship and determining the corresponding parameters could be avoided, and the simulation results tended to being realer. In addition, on the base of similitude between the reduced-scale model and the prototype, the gravitational field of the model absolutely equaled that of the prototype. The analysis results indicated that the reduced-scale model could basically reappeared properties of stress, strain, distortion and so on.

The factors of the pile's diameter, the pile's material rigidities and internal frictional coefficient $\mu$ of soil around the pile were analyzed in detail to find different quantity influences on the mechanics characters of horizontal displacements of the pile and the p-y curve in the article. Based on the similarity of the reduced-scale model to the prototype, the numerical simulation results indicated that the connection of microscopic structural change with macroscopic mechanical action, the bearing behavior of the laterally loaded pile, and microscopic structural response could be simulated well by 3D DEM. However, since it was ambiguous of the corresponding relationships between microscopic parameters and macroscopic model parameters, only qualitative and semi-quantitative researches of the model have been done, but it was difficult to contrast with the theoretical calculation results in detail, which was the further study when distinct element procedure was applied.

\section{References}

[1] Wu Hengli. Solutions of laterally loaded piles by composite stiffness principle with biparameter method (second edition). Beijing: People transportation press, 2000.

[2] Liu Wenbai. Experimental study and particle flow code numerical simulation of extended foundation with aeolian sand under the action of uplift loading. Shanghai: Doctoral dissertation. Tongji University, 2003.

[3] Cundall P A, Strack O D L. A discrete numerical model for granular assembles[J]. Geotechnique, 1979, 29(1): 47-65.

[4] Ricard Ramos. Centrifuge Study of Bending Response of Pile Foundation to a Lateral Spread Including Restraining Effect of Superstructure [D]. New York: Doctor of Philosophy. Rensselaer Polytechnic Institute Troy, New York,1999.

[5] Broms BB. Lateral resistance of piles in cohesionless soils. J Soil Mech Found Div ASCE 1964;90(3):123-56.

[6] O’Neill MW, Murchison JM. An evaluation of p-y relationships in sands. Research Report No. GT-DF02-83, Department of Civil Engineering, University of Houston; 1983.

[7] Reese LC, Cox WR, Koop FD. Analysis of laterally loaded pile in sand. In: Proceedings of the Sixth annual offshore technology conference, Houston (TX). Paper no. 2080; 1974.

[8] Briaud JL, Smith TD, Meyer BJ. Using the pressuremeter curve to design laterally loaded piles. In: Proceedings of the fifteenth annual offshore technology conference. Houston, (TX). Paper no. 4501; 1983.

[9] Chia-Cheng Fan, James H.Long. Assessment of existing methods for predicting soil response of laterally loaded piles in sand. Computers and Geotechnics, 2005, 32:274-289. 